\title{
Identity Formation in Adolescents from Italian, Mixed, and Migrant Families
}

\author{
Elisabetta Crocetti · Alessandra Fermani · Barbara Pojaghi • \\ Wim Meeus
}

Published online: 22 June 2010

(C) Springer Science+Business Media, LLC 2010

\begin{abstract}
The purpose of this study was to compare identity formation in adolescents from Italian $(n=261)$, mixed $(n=100)$, and migrant families $(n=148)$. Participants completed the Italian version of the Utrecht-Management of Identity Commitments Scale that assesses identity processes in educational and relational domains. Within a variablecentered approach we found that adolescents from migrant families reported significantly higher levels of reconsideration of commitment than did their peers from Italian and mixed families. Similarly, within a person-centered approach, adolescents from migrant families were more represented in the searching moratorium status than their counterparts from Italian and mixed families. Overall, these results indicated that migrant adolescents face more difficulties to define their personal identity.
\end{abstract}

Keywords Adolescence - Identity processes - Identity statuses · Italian families · Mixed families · Migrant families

\section{Introduction}

Identity development is a core developmental task of adolescence (Erikson 1950, 1968). In fact, the biological (the experience of puberty), cognitive (the acquisition of the formalabstract reasoning), and social (the starting of new interactions with peers and modifications in parent-adolescent relationships) changes that characterize this period of the life span stimulate adolescents to find out their own personal identity (Kroger 2004). Furthermore, in our contemporary Western societies people are strongly pressed to find their own unique identity by choosing among a large variety of alternatives, in a situation named

\footnotetext{
E. Crocetti $(\bowtie) \cdot$ A. Fermani · B. Pojaghi

Department of Educational Sciences, University of Macerata, Postbox: Piazzale Luigi Bertelli

(Contrada Vallebona) 62100, Macerata, Italy

e-mail: elisabetta.crocetti@unimc.it
}

W. Meeus

Research Centre on Adolescent Development, University of Utrecht, Postbox 80140, 3508 TC Utrecht, The Netherlands 
the "tyranny of freedom" (Schwartz 2000). This expression underlines that to have several opportunities is not always gratifying, especially when people do not have a criterion to choose what is best for them, since societal guidelines and meaningful referential frameworks are missing (Baumeister 1987; Baumeister and Muraven 1996; Berzonsky 2003; Ferrer-Wreder et al. 2002).

Additionally, Western societies are becoming more and more multicultural. Therefore, it is important to understand how adolescents belonging to different ethnic groups develop their identity (Schwartz 2005). Until now, most studies focused on identity formation in different ethnic groups have been conducted in the USA or in European countries, like The Netherlands and the United Kingdom, in which immigration has historically been a prominent phenomenon. Less is known about countries, like Italy, in which immigration is a more recent phenomenon (Mancini 2007).

In fact, after being a country of mass emigration for decades (up till the end of the 1960s), Italy has recently become a country of increasing immigration (King 1993). The Italian National Statistical Institute (ISTAT 2008a) reported that, in 2007, adolescents from migrant families (aged 0-17 years) represented 6.6\% of the general Italian population.

This contribution investigates identity in adolescents who migrated with their families to Italy. In order to detect whether these adolescents face specific difficulties in developing their identity, they will be compared to their peers from Italian families and to their peers from mixed families, in which only one parent had the Italian nationality. Before presenting our study and its related evidence, we will review the main literature on identity and ethnicity.

\section{Identity Formation: Statuses and Processes}

Erikson $(1950,1968)$ proposed a developmental theory of the life span, which consisted of eight phases. Each phase is characterized by a core conflict which individuals struggle to resolve. The degree of success or failure in resolving each conflict is likely to affect future adjustment and may help or hinder the resolution of future conflicts associated with successive phases to come. In adolescence the key developmental task is the achievement of identity. Erikson (1968) conceptualized ego identity both as a conscious sense of individual uniqueness and as an unconscious striving for continuity of experience. Adolescents may move toward two poles: identity achievement and identity confusion. Identity achieved individuals have combined and integrated relevant earlier identifications into a unique and personal mold. On the contrary, young people in a status of identity confusion have not chosen their own commitments and, thus, they move from one identification to another one.

Adolescents, in order to find which choices to become committed to, may go through an identity crisis (Erikson 1968). This experience can be of course painful, but at the same time, it represents a challenging turning point in individual personal life, necessary to achieve healthy adult identity. A further key concept of Erikson's (1968) theory concerned the centrality of the interplay between individual and context (Adams and Marshall 1996), that implies it is not possible to understand personal development without taking into account the contexts in which this occurs (Bosma and Kunnen 2001).

The most popular elaboration of Erikson's views on identity formation is Marcia's (1966) identity status paradigm, according to which four identity statuses can be derived from the combination of two key variables: exploration and commitment. Exploration refers to the active questioning and weighing of various identity alternatives before making decisions about the values, beliefs, and goals to pursue. Commitment involves making a relatively firm choice about an identity domain and engaging in significant activities geared 
toward the implementation of that choice. Four identity statuses have been obtained by crossing exploration and commitment: in the achievement status, adolescents have made a commitment in a specific identity domain, following a period of active exploration; in the foreclosure status, adolescents have made a commitment without any or little exploration; in the moratorium status, adolescents are actively exploring various alternatives and have not yet made a commitment; finally, in the diffusion status adolescents have not engaged in a pro-active process of exploration of different alternatives, nor have they made a commitment in a specific identity domain. A large amount of research has been conducted within the identity status paradigm. Evidence collected revealed that the identity statuses could be clearly differentiated in terms of personality characteristics, psychosocial problems and well-being, cognitive processes, interpersonal behaviors, and family antecedents (for reviews see Marcia 1993; Kroger 2003).

Identity status research has been guided by the intent of providing a classification of individuals, rather than studying the process of identity development (Bosma 1985). The identity statuses were conceived as various outcomes of the adolescent period described by Erikson's theory (Meeus et al. 2002). However, Grotevant (1987), Stephen et al. (1992), and Marcia (1993) himself recognized the importance of studying the process of identity formation rather than focusing exclusively on its outcomes. In the last three decades various extensions of the identity status model have been proposed (for a review see Schwartz 2001). In particular, European scholars have advanced the identity field by focusing on different forms of exploration and commitment (Bosma 1985; Luyckx et al. 2006, 2008; Meeus 1996; Meeus et al. 2002) and suggesting additional identity statuses not encompassed in Marcia's original work (e.g., Luyckx et al. 2008; Meeus et al. in press).

Within this renewed line of research, Crocetti et al. (2008b), building upon previous work by Meeus (Meeus 1996; Meeus et al. 1999, 2002), proposed an identity model that comprises three core processes: commitment, in-depth exploration, and reconsideration of commitment. Specifically, commitment refers to enduring choices that adolescents have made with regard to various developmental domains and to the self-confidence they derive from these choices. In-depth exploration represents the extent to which adolescents think actively about the commitments they have enacted, reflect on their choices, search for additional information about their commitments, and talk with others about them. Reconsideration of commitment refers to the comparison of present commitments with possible alternative commitments because the current ones are no longer satisfactory. The authors demonstrated, through confirmatory factor analysis, that this three-factor model provided the best fit to the data in large samples of European adolescents from the Netherlands (Crocetti et al. 2008b) and Italy (Crocetti et al. 2010b), for boys and girls, separately, and also for both early and middle adolescents. Additionally, the Dutch study established interethnic equivalence of the model in that it also fit well for ethnic minority individuals living in the Netherlands. Therefore, this model represents a useful theoretical and methodological framework to investigate the development of identity across ethnic groups.

This three-factor model includes a dual cycle process. It is assumed that individuals approach adolescence with a set of commitments of at least minimal strength in ideological and interpersonal identity domains (Meeus in press; Meeus et al. in press). Thus, adolescents can then explore their commitments in-depth and decide whether they match their potentials and goals (the identity formation and maintenance cycle). If adolescents realize their current commitments do not fulfill their aspirations, they might reconsider them in favor of other commitments (the identity revision cycle). 
Following the classification system used by Marcia (1966) for the identity statuses, combining levels of commitment, in-depth exploration, and reconsideration of commitment creates five unique identity statuses (Crocetti et al. 2008a): achievement (high commitment and in-depth exploration, but low reconsideration of commitment), early closure (moderate commitment, low exploration, and low reconsideration), moratorium (low commitment, low exploration, and high reconsideration), searching moratorium (high commitment, exploration, and reconsideration), and diffusion (low commitment, exploration, and reconsideration). Studies conducted with both Dutch (Crocetti et al. 2008a) and Italian adolescents (Crocetti et al. 2010a), pointed out that the combination of these three identity processes could highlight the distinction between two types of moratorium: the moratorium status is characterized by the attempt to find a fulfilling commitment, while the searching moratorium status is defined by the effort to revise an existing commitment (for an example about the distinction between these two moratorium statuses see Crocetti et al. 2008a, p. 993). Thus, individuals in the searching moratorium can look for new commitments starting their search from a secure basis, represented by the commitments they already have.

Each of the five statuses revealed a theoretically meaningful and distinct profile on personality, problem behavior, and parent-adolescent relationship dimensions (Crocetti et al. 2008a). In particular, the adolescents in the achievement status displayed the healthiest personality profile; they had few psychosocial problems and reported perceptions of good quality parent-adolescent relationships. The adolescents in the early closure status, on the one hand, were similar to the former individuals in reporting low psychosocial problems and good parental communication. They were, on the other hand, different with respect to their personality profile. Indeed, they were less extroverted, agreeable, conscientious, and open to experience than adolescents in achievement, even though they reported high emotional stability. The moratorium and searching moratorium statuses both represented crisis groups. However, the moratorium status appeared to be much more troubled than the searching moratorium one, as revealed by higher scores on various psychosocial problems. Finally, adolescents in the diffusion status displayed a personality profile similar to that of adolescents in the early closure status. Furthermore, they exhibited low levels of psychosocial problems and some ambivalence in their relationships with their parents.

\section{Ethnicity and Identity Formation}

The identity formation task might be more difficult for adolescents belonging to ethnic minority groups. This can be due to various factors. First, adolescents from migrant families need to consider a larger array of values and norms, provided both by their family traditions and by the culture of the hosting society (e.g., Berry 2001; Phalet and Schönpflug 2001). It is not always easy for them to find a balance between often contrasting cultural systems, especially when the family background promotes collectivism, whereas the hosting society emphasizes individualism (Triandis 2001). Second, adolescent attempts to explore different alternatives are sometimes impeded by family obligations, and other times they are hampered by prejudices displayed by the hosting society (e.g., Kosic et al. 2005; Verkuyten and Kinket 2000).

A number of studies, conducted in the United States, have tested whether it is possible to individuate identity differences between adolescents from minority ethnic groups and their Caucasian peers. These studies have focused on identity domains common to all 
adolescents, that can be clustered in two groups: the ideological (choices in the areas of education/occupation, politics, religion, and philosophical life style) and the relational (choices in the areas of friendship, dating, sex roles, and recreation) identity domains. Studies conducted in the USA pointed out contrasting findings, with some studies reporting differences (Abraham 1986; Streitmatter 1988) not confirmed by other investigations (Branch et al. 2000; Grove 1991; Rotheram-Borus 1989).

Specifically, Abraham (1986) found that Mexican/American adolescents were more foreclosed than their Euro/American peers on ideological identity. Similarly, Streitmatter (1988) found that ethnic minority adolescents (i.e., Hispanic, African, Native American, and Asian adolescents were grouped together) were more foreclosed than their Euro/ American peers on both ideological and interpersonal identity.

On the contrary, Rotheram-Borus (1989) found no differences in ideological identity statuses displayed by Euro/American, African/American, Puerto Rican, and Filipino adolescents. Similarly, Grove (1991) reported no differences in the number of Euro/ American and Asian college students classified in the achievement status in various identity areas (i.e., occupation, religion, politics, sex roles, sexual attitudes, and race). Also Branch et al. (2000) found no differences on global identity statuses (obtained combining ideological and interpersonal domains) exhibited by Euro/American, African/American, Latino/Hispanic, and Asian American adolescents.

Recently, Crocetti et al. (2008a) examined differences on identity statuses (obtained combining ideological and interpersonal domains) in youth living in the Netherlands. In particular Dutch adolescents were compared to their ethnic minority peers whose families mainly come from non-Western countries, such as Morocco, Turkey, and Surinam. Findings revealed that Dutch adolescents were more strongly present in early closure (35.7 vs. $23.4 \%$ ) and diffusion ( 28 vs. $13.5 \%$ ) statuses than ethnic minority adolescents. On the other hand, ethnic minority adolescents were more present in the moratorium (30.3 vs. $19.6 \%$ ) and searching moratorium (20.7 vs. $7.1 \%$ ) statuses than Dutch adolescents were, while no differences were found on the achievement status. Therefore, these results clearly demonstrated that adolescents from ethnic minority groups were more present in the identity statuses of moratorium (both searching moratorium and moratorium) than were their Dutch peers, and thus, were struggling to find their own identity.

Taken together, studies focused on ethnic differences on identity formation point out an intriguing picture. It is difficult to make generalizations, since findings depend on the ethnic groups considered, on the identity domains that are examined, and on the country in which the study is conducted. It is also necessary to investigate this issue in countries in which immigration is a more recent phenomenon and, therefore, less is known about how adolescents from migrant families deal with the identity formation task (Schwartz 2005).

\section{The Present Study}

On the basis of the literature reviewed so far, the purpose of the present study, conducted in Italy, was to examine identity formation in adolescents from migrant families, that were compared to their peers from Italian families and to those from mixed families in which one parent was Italian and the other had a non-Italian nationality. In order to detect differences between adolescents from Italian, mixed, and migrant families a variablecentered and a person-centered approach were integrated (Goossens and Luyckx 2007; von Eye and Bogat 2006).

Using a variable-centered approach we investigated mean differences in identity processes considering the three-factor identity model proposed by Crocetti et al. (2008b, 
2010b). Thus, we examined whether levels of endorsement of commitment, in-depth exploration, and reconsideration of commitment varied significantly among adolescents from Italian, mixed, and migrant families.

By adopting a person-centered approach, we tested whether the distribution of youth from the three groups along five identity statuses (i.e., achievement, early closure, diffusion, moratorium, and searching moratorium; Crocetti et al. 2008a; Meeus et al. in press) was significantly different.

\section{Method}

Participants

Participants were 509 adolescents (55\% boys and $45 \%$ girls) attending various junior high and high schools in the east-central region of Italy, and ranging in age from 11 to 19 years $(M=13.6 ; \mathrm{SD}=2.2)$. Participants were drawn from a larger project on Italian adolescents' identity formation that involved more than 2000 adolescents. From this sample we selected all adolescents from migrant $(n=148)$ and mixed families $(n=100)$ and a subsample of youth from Italian families $(n=261)$ that could be compared in terms of gender, age, and parental educational background to adolescents from mixed and migrant families. The description of the demographic characteristics of participants from Italian, mixed, and migrant families is provided in Table 1 . The three groups were not statistically different in terms of age $\left(F(2,509)=2.08, n s, \eta^{2}=.01\right)$, gender $\left(\chi^{2}(2)=0.23, n s\right)$, or paternal educational background $\left(\chi^{2}(2)=0.20, n s\right)$; additionally differences on maternal educational background were close to significance without reaching it $\left(\chi^{2}(2)=5.78\right.$, $p=.06$ ).

Within the 100 mixed families, 40 fathers had a non-Italian nationality: 14 fathers came from North and Central European countries, 10 from Africa, 9 from South America, 5 from South and Eastern Europe, 1 from Middle East, and 1 from Australia. Sixty mothers had a non-Italian nationality: 18 came from South and Eastern European countries, 17 from North and Central Europe, 12 from Central and South America, 6 from Africa, 3 from the USA, 1 from Australia, 1 from Asia, and 2 indicated that they had a non Italian nationality but they did not specify their nationality.

Within the 148 migrant families, 61 came from South and Eastern Europe, 36 from Africa, 29 from Asia, 20 from Central and South America, and 2 from France. In each migrant family the marital couple had the same nationality.

Table 1 Demographic characteristics of the adolescents from Italian, mixed, and migrant families

\begin{tabular}{lccc}
\hline & $\begin{array}{l}\text { Adolescents from } \\
\text { Italian families } \\
(n=261)\end{array}$ & $\begin{array}{l}\text { Adolescents } \\
\text { from mixed } \\
\text { families }(n=100)\end{array}$ & $\begin{array}{l}\text { Adolescents from } \\
\text { migrant families } \\
(n=148)\end{array}$ \\
\hline Age in years: Mean (SD) & $13.40(2.25)$ & $13.87(2.12)$ & $13.70(1.99)$ \\
Gender: Boys: $n(\%)$ & $144(55.2 \%)$ & $53(53 \%)$ & $83(56.1 \%)$ \\
Education Father: High: $n(\%)$ & $35(15.0 \%)$ & $15(16.9 \%)$ & $14(14.9 \%)$ \\
Education Mother: High: $n(\%)$ & $38(16.6 \%)$ & $25(27.5 \%)$ & $15(15.8 \%)$ \\
\hline
\end{tabular}

High educational level corresponds to the university degree 
Measures

\section{Identity}

All participants completed the Italian version (Crocetti et al. 2010b) of the UtrechtManagement of Identity Commitments Scale (U-MICS; Crocetti et al. 2008b). The UMICS consists of 13 items with a response scale ranging from 1 (completely untrue) to 5 (completely true). Following instructions provided by Crocetti et al. (2008b) we measured identity dimensions in one ideological domain (education) and in one interpersonal domain (friendship), since these two domains are very important for most adolescents (Bosma 1985). Thus, we summed responses across the two domains (Crocetti et al. 2008b) to obtain global identity scores. Specifically, 10 items measure commitment, 10 items assess in-depth exploration, and 6 items tap reconsideration of commitment. Sample items include: "My education/best friend gives me certainty in life" (commitment), "I think a lot about my education/best friend" (in-depth exploration), and "I often think it would be better to try to find a different education/best friend" (reconsideration of commitment). Using Cronbach's alphas, the reliability of the U-MICS subscales was found to be adequate with values of $.79, .79$, and .75 for commitment, $.65, .71$, and .70 for in-depth exploration, $.66, .69$, and .70 for reconsideration of commitment in adolescents from Italian, mixed, and migrant families, respectively.

\section{Results}

\section{A Variable-Centered Approach: Identity Processes}

The first aim of this study was to examine whether adolescents from Italian, mixed, and migrant families differed in levels of endorsement of identity processes. ${ }^{1}$ In order to reach this aim we performed a Multivariate Analysis of Variance (MANOVA) on commitment, in-depth exploration, and reconsideration of commitment, with the three groups (Italian, mixed, and migrant) as the independent variables. Gender and age (early vs. middle adolescents) were also included as independent variables to control whether differences between adolescents from the three groups could be moderated by gender and age.

Results indicated that, according to Wilks' Lambda criterion, the combined dependent variables were significantly affected by group membership (adolescents from Italian vs. mixed vs. migrant families) $\left(F(6,990)=4.68, p<.001, \eta^{2}=.03\right)$, but not by interactions between group membership and gender $\left(F(6,990)=0.18, n s, \eta^{2}=.00\right)$, and between group membership and age $\left(F(6,990)=1.09, n s, \eta^{2}=.00\right)$ categories.

Results of the follow-up univariate analyses (see Table 2) and Tukey post hoc comparisons highlighted that adolescents from migrant families scored significantly higher on reconsideration than adolescents from Italian and mixed families.

To further explore levels of endorsement of identity processes within adolescents from migrant families, we compared youth from Eastern European, African, Asian, and SouthAmerican families. ${ }^{2}$ Results of a MANOVA indicated that adolescents coming from these areas scored differently on reconsideration of commitment $(F(3,146)=2.91, p<.05$,

\footnotetext{
1 Preliminary analyses indicated that our data met assumptions of homogeneity of variances and normality. Furthermore, no univariate or multivariate outliers were detected.

2 The 2 adolescents from migrant French families were not included in this analysis.
} 
Table 2 Mean scores (and standard deviations in parentheses) of identity processes in adolescents from Italian, mixed, and migrant families

\begin{tabular}{llllrr}
\hline Identity processes & $\begin{array}{l}\text { Adolescents from } \\
\text { Italian families }\end{array}$ & $\begin{array}{l}\text { Adolescents from } \\
\text { mixed families }\end{array}$ & $\begin{array}{l}\text { Adolescents from } \\
\text { migrant families }\end{array}$ & $F(2,509)$ & $\eta^{2}$ \\
\hline Commitment & $3.59(0.59)$ & $3.48(0.59)$ & $3.61(0.59)$ & 1.71 & .01 \\
$\begin{array}{l}\text { In-depth exploration } \\
\begin{array}{l}\text { Reconsideration } \\
\quad \text { of commitment }\end{array}\end{array}$ & $3.25(0.53)$ & $3.22(0.59)$ & $3.25(0.58)$ & 0.19 & .00 \\
\hline
\end{tabular}

*** $p<.001$. A mean is significantly different from another mean at $p<.01$ if they have different superscripts. A mean without a superscript is not significantly different from any other mean

$\left.\eta^{2}=.06\right)$. In particular, Tukey post comparisons pointed out that Asian adolescents $(M=3.22 ; \mathrm{SD}=0.59)$ scored significantly higher than African youth $(M=2.69$; $\mathrm{SD}=0.77)$ on reconsideration of commitment, while South-American $(M=2.87$; $\mathrm{SD}=0.78)$ and Eastern European adolescents $(M=2.82$; SD $=0.79)$ reported intermediate levels of reconsideration, that were not significantly different from those of their counterparts from Asia and Africa.

\section{A Person-Centered Approach: Identity Statuses}

The second purpose of this study was to examine whether adolescents from Italian, mixed, and migrant families were differently represented within the various identity statuses. In order to reach this aim we performed a cluster analysis to empirically obtain identity statuses from the combination of identity processes (i.e., commitment, in-depth exploration, and reconsideration of commitment). Based on the existing literature we looked for a five-cluster solution (Crocetti et al. 2008a, 2010a). We followed the two-step clustering procedure suggested by Gore (2000) running the analyses in the total sample. In the first step, a hierarchical cluster analysis was conducted using Ward's method on squared Euclidian distances. In the second step, the initial cluster centers, obtained from the hierarchical cluster analysis, were used as non-random starting points in an iterative $k$ means clustering procedure.

The final 5-cluster solution we obtained clearly replicated the solution found in studies with both Dutch (Crocetti et al. 2008a) and Italian (Crocetti et al. 2010a) adolescents. This solution reported a very good explanatory power, as it explained $60 \%$ of the variance in commitment, $58 \%$ of the variance in in-depth exploration, and $57 \%$ of the variance in reconsideration of commitment. ${ }^{3}$

The $Z$-scores for commitment, in-depth exploration, and reconsideration of commitment for the five clusters are shown in Fig. 1 . The achievement cluster $(n=132 ; 25.9 \%)$ consisted of adolescents scoring high on commitment and in-depth exploration, but low on reconsideration of commitment. The early closure cluster $(n=124 ; 24.4 \%)$ was composed of individuals with moderately high scores on commitment, associated with low scores on in-depth exploration and low scores on reconsideration of commitment. The moratorium cluster $(n=107 ; 21 \%)$ comprised youth who scored low on commitment and in-depth

\footnotetext{
${ }^{3}$ When the cluster analysis was repeated only in the sub-group of adolescents from migrant families, the same 5-cluster solution emerged. It explained $59 \%$ of the variance in commitment, $67 \%$ of the variance in in-depth exploration, and $55 \%$ of the variance in reconsideration of commitment. Taken together these findings indicate the robustness of the 5-cluter solution and its replicability in different groups.
} 


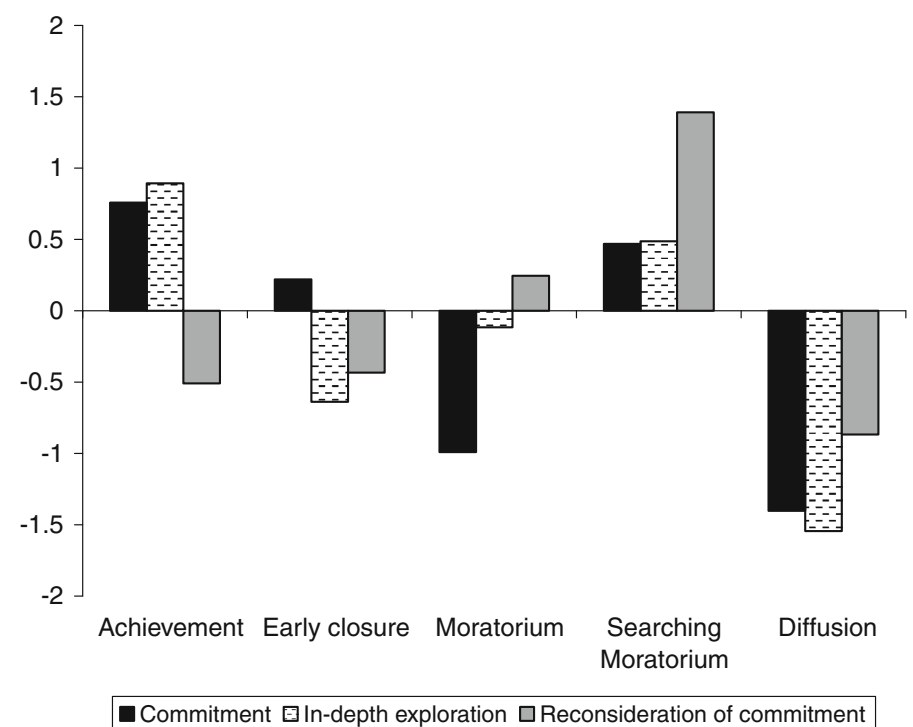

Fig. 1 Z-scores for commitment, in-depth exploration, and reconsideration of commitment for the five identity clusters

exploration, and moderate high on reconsideration of commitment. The searching moratorium cluster ( $n=98 ; 19.3 \%$ ) consisted of adolescents scoring high on commitment, high on in-depth exploration, and particularly high on reconsideration of commitment. The diffusion cluster $(n=48 ; 9.4 \%)$ included individuals low on commitment, in-depth exploration, and reconsideration of commitment.

By means of the Chi Square Test $\left(\chi^{2}(8)=17.11, p<.05\right)$ we found significant differences on the distribution of adolescents from different families along the five identity statuses (see Table 3). In particular, adolescents from migrant families were more likely to be in the status of searching moratorium than their peers from Italian or mixed families.

Furthermore, we explored, within the group of youth from migrant families, differences on identity statuses exhibited by adolescents coming from various regions. Fisher's Exact Test (using Monte Carlo approximation to deal with issues related to small sub-samples) revealed that adolescents from Eastern European, African, Asian, and South-American families differed significantly in their distribution across the clusters $(p=.05)$. As can be seen in Table 4, Asian adolescents were clearly differentiated from their counterparts from other regions. In particular they were overrepresented in the searching moratorium status.

\section{Discussion}

This study examined identity formation in three groups living in Italy: adolescents from migrant families were compared to their peers from Italian and mixed families. Using both a variable-centered and person-centered approach (Goossens and Luyckx 2007; von Eye and Bogat 2006), we found large differences on identity processes and statuses in domains common to all adolescents (i.e., educational and relational domains). 
Table 3 Percentages of adolescents from Italian, mixed, and migrant families in the five identity statuses

\begin{tabular}{llll}
\hline Identity statuses & $\begin{array}{l}\text { Adolescents from } \\
\text { Italian families }(\%)\end{array}$ & $\begin{array}{l}\text { Adolescents from } \\
\text { mixed families }(\%)\end{array}$ & $\begin{array}{l}\text { Adolescents from } \\
\text { migrant families }(\%)\end{array}$ \\
\hline Achievement & 29.1 & 26.0 & 20.3 \\
Early closure & 24.5 & 25.0 & 23.6 \\
Moratorium & 23.0 & 19.0 & 18.9 \\
Searching moratorium & $14.9^{\mathrm{a}}$ & $16.0^{\mathrm{a}}$ & $29.1^{\mathrm{b}}$ \\
Diffusion & 8.4 & 14.0 & 8.1 \\
Total & 100 & 100 & 100
\end{tabular}

A percentage is significantly different from another percentage at $p<.01$ if they have different superscripts.

A percentage without a superscript is not significantly different from any other percentage

Table 4 Percentages of adolescents from different migrant families in the five identity statuses

\begin{tabular}{lllll}
\hline Identity statuses & \multicolumn{2}{l}{ Migrant families from... } \\
\cline { 2 - 5 } & $\begin{array}{l}\text { Eastern Europe } \\
(n=61)(\%)\end{array}$ & $\begin{array}{l}\text { Africa } \\
(n=36)(\%)\end{array}$ & $\begin{array}{l}\text { Asia } \\
(n=29)(\%)\end{array}$ & $\begin{array}{l}\text { South-America } \\
(n=20)(\%)\end{array}$ \\
\hline Achievement & 23.0 & 22.2 & 10.3 & 20.0 \\
Early closure & 29.5 & 27.8 & 6.9 & 25.0 \\
Moratorium & 18.0 & 22.2 & 20.7 & 15.0 \\
Searching moratorium & $19.7^{\mathrm{a}}$ & $27.8^{\mathrm{a}}$ & $55.2^{\mathrm{b}}$ & $25.0^{\mathrm{a}}$ \\
Diffusion & 9.8 & 0 & 6.9 & 15.0 \\
Total & 100 & 100 & 100 & 100 \\
\hline
\end{tabular}

A percentage is significantly different from another percentage at $p<.01$ if they have different superscripts. A percentage without a superscript is not significantly different from any other percentage

\section{A Variable-Centered Approach: Differences on Identity Processes}

By means of a variable-centered approach we compared mean levels of commitment, indepth exploration, and reconsideration of commitment (Crocetti et al. 2008b; Meeus in press). Adolescents from Italian, mixed, and migrant families reported similar levels of commitment and in-depth exploration, whereas they showed differences on endorsement of reconsideration of commitment. In fact, adolescents from migrant families reconsidered their choices to a greater extent than their counterparts from both Italian and mixed families.

High levels of reconsideration of commitment represent an identity crisis (Erikson 1968), since they suggest adolescents perceive their current commitments as no longer fitting their interests, values, and standards. In fact, reconsideration of commitment has been found to be linked to an unstructured personality profile, to be positively related to internalizing as well as externalizing problem behaviors, and to be associated with indicators of a poor parent-adolescent relationship (Crocetti et al. 2008b).

Thus, although in the long-term reconsideration of commitments might foster formation of a firm identity, stimulating abandonment of unsatisfying choices in favor of better commitments, in the short-term reconsideration is associated with a condition of identity 
distress (Berman et al. 2004; Crocetti et al. 2010b). This contention is supported by empirical evidence provided by Schwartz et al. (2009) that clearly demonstrated that past exploration fosters adaptive psychosocial functioning (i.e., high self-esteem, purpose in life, internal locus of control, and high ego-strength) and reduces proclivity toward externalizing symptoms (i.e., impulsivity and tolerance for deviance) by reducing identity confusion. On the contrary, present exploration hampers adaptive functioning and stimulates both internalizing problems (i.e., depression and anxiety) and proclivity toward externalizing symptoms by creating identity confusion.

These considerations, applied to the condition of the migrant adolescents, suggest that reconsideration of current commitments and exploration of alternative possibilities might support finding of fulfilling commitments and, therefore, achievement of a future firm identity that fosters adaptive functioning and well-being. However, these positive outcomes are postponed until the future, whereas at the time when reconsideration occurs, this is mainly associated with identity distress and problem behaviors (Berman et al. 2004; Crocetti et al. 2008b, 2010b).

\section{A Person-Centered Approach: Differences on Identity Statuses}

Findings obtained by means of a variable-centered approach were consistent with those found through a person-centered approach. The distribution of participants across identity statuses (i.e., achievement, early closure, moratorium, searching moratorium, and diffusion) revealed that adolescents from migrant families were more often represented in the searching moratorium group than their peers from Italian and mixed families. Adolescents in the searching moratorium status are going through an identity revision (Crocetti et al. 2008a), meaning that they are letting go their current commitments and are looking for other possibilities. This status is characterized by a condition of identity disequilibrium and distress (Berman et al. 2004), even though it is not as problematic as the moratorium status, in which adolescents are struggling to find their own commitments but, at the moment, they cannot count on any leading commitment (Crocetti et al. 2010a; for a review on the problem behavior typical of the moratorium status see Meeus et al. 1999). Identity distress is associated with both internalizing and externalizing problem behaviors (Berman et al. 2009; Hernandez et al. 2006) and, therefore, may exacerbate conditions of adolescents from migrant families. Thus, adolescents from migrant families are a primary target for psychosocial interventions aimed at promoting positive youth development (Berman et al. 2001; Ferrer-Wreder et al. 2002; Kurtines et al. 2008; we will return to this issue in the implications section).

\section{Identity Formation in Adolescents from Mixed Families}

Overall, findings of this study indicated that adolescents from mixed families (in which one parent was Italian and the other had a non-Italian nationality) did not differ from their Italian peers in terms of identity formation. Various explanations of these findings might be advanced. First, it is important to underline that $37 \%$ of adolescents within the mixed family group had one parent coming from North Europe, USA, or Australia. Within the Italian context, these binational families are similar to Italian families because they are composed of people with a similar cultural background (Gozzoli and Regalia 2005). Thus, adolescents from these mixed families may not consider themselves, nor would they be considered by others, as drastically different from their Italian peers, at least in educational and interpersonal identity domains. For the other $63 \%$ of adolescents from binational 
families, in which one parent came from an Eastern European, South-American, African, or Asian country, we might hypothesize that the difficulties of finding a balance between paternal and maternal cultural systems are compensated by the opportunity of being in this condition (Gozzoli and Regalia 2005). In fact, offspring of mixed families can benefit from being reared in a multicultural context. For instance, Gozzoli and Regalia (2005) found, in a qualitative study conducted with mixed families living in Italy, that parental couples believe that growing up in a mixed family would foster in their children mental flexibility, tolerant attitudes, and a greater ability to adjust to changing situations, all factors that can promote positive youth development.

\section{Identity Formation in Adolescents from Migrant Families}

An in-depth analysis within the group of adolescents from migrant families pointed out this was not an homogeneous group. In fact, findings referring to the overall migrant group were particularly visible in the Asian sub-group. Specifically, adolescents from Asian migrant families displayed higher reconsideration of commitment than their peers from Africa, South America, and Eastern Europe. Additionally, Asian adolescents were overrepresented in the searching moratorium status, with more than half of them being in this condition.

These findings underline the importance of studying specific migrant groups. In fact, even though migrant families share similar motivations as the impetus for migration (i.e., the Italian National Institute of Statistics [ISTAT 2008b] reported that, in 2007, 92.2\% of migrants came to Italy to find a job or to rejoin one's family member already come to Italy for work reasons), their integration paths may differ widely. For adolescents from migrant families the challenge of forming a firm personal educational and relational identity is strongly entangled with the development of social identity (Tajfel 1981). These adolescents need to find out which is their place within the social system and which groups they identify with (Berry 2001). This choice is not easy because they may be coping with limitations imposed by their family or by the hosting society (Kosic et al. 2005). The increasing hostility that adolescents from migrant families have to face is proved by the results of political elections. In fact, in the last European political elections held in 2009 in Italy a right-wing party (i.e., Lega Nord), which stresses the urgency of limiting immigration, received $10.20 \%$ of the vote (in elections of 2004 they received the $5 \%$ of the vote), and in North-Italy, where the number of migrants is higher than in the rest of Italy, they received $19 \%$ of the vote. ${ }^{4}$ The preference for this party was even stronger in the last local elections held in 2010. Thus, for migrant adolescents the possibility to explore different identity alternatives in order to find personal commitments is tempered by intergroup relationships that may limit youth opportunities.

\section{Implications}

Briefly, our findings suggest that adolescents from migrant families, especially those belonging to Asian groups, display difficulties in forming their identity in educational and relational realms. These adolescents display high levels of reconsideration of commitment that are associated with both internalizing and externalizing problem behaviors (Crocetti et al. 2008b). Furthermore, they are overrepresented in the status of searching moratorium, which indicates a condition of identity disequilibrium and distress (Crocetti et al. 2008a).

\footnotetext{
${ }^{4}$ Official data provided by the Italian Interior Ministry available at http://elezioni.interno.it/.
} 
Therefore, adolescents from migrant groups are a primary target for identity interventions (Ferrer-Wreder et al. 2002). The aim of these interventions should be to promote critical evaluation of identity alternatives in order to find a set of fulfilling commitments (Berman et al. 2001; Kurtines et al. 2008; Schwartz 2001). In order to be more effective, interventions should involve different systems, which directly and indirectly impact adolescent development (Bronfenbrenner 1979).

At the first level, it is important to work on peer microsystems. Most identity interventions have adopted a group participatory format, in which the group provides a suitable context for discussion and evaluation of various possibilities (Schwartz and Pantin 2006). Furthermore, the group format offers to each participant the possibility of identifying with other members that are actively addressing the identity formation task. Interventions focused on group discussion may be organized in two different ways that could complement each other. In the first group context, migrant adolescents might compare their experiences with those of other peers in similar situations. Thus, migrant adolescents could first share their difficulties and solving strategies with peers belonging to their same ethnic group and, therefore, subjected to similar cultural and religious family heritage (Ketner et al. 2004). Second, migrant adolescents could discuss their experiences with Italian peers. This context would provide an opportunity for inter-group contacts. In fact, experimental studies conducted with Italian youth (cf. Voci and Hewstone 2003) clearly demonstrated that contacts with immigrants had direct positive effects on perceived out-group variability and out-group attitude, and a direct negative effect on subtle prejudice. Thus, contact between Italian and migrant adolescents can be useful to reduce prejudice displayed by Italian youth, and, as a consequence, to provide to migrant adolescents with a context in which they can more freely compare themselves with their Italian peers and explore their cultural and value system.

At a second level, it would be useful to create stronger interconnections between two microsystems with which adolescents interact daily, that is the family and school systems. In fact, often adolescents from migrant families live in two parallel systems that never interact. For instance, Phalet and Schönpflug (2001) found that, in Moroccan and Turkish families living in the Netherlands, mainly collectivistic values were transmitted from parents to offspring. On the other hand, ethnic minority adolescents were also exposed to more individualistic principles through mass-media communication, attendance in public schools, and interaction with their Dutch peers. These data underline the need to develop intercultural projects, involving Italian and migrant families and the schools, aimed at creating a shared sense of community (Battistich et al. 2004; Salmivalli and Isaacs 2005).

At a final level, it is necessary to work on the larger socio-cultural context, which is the macrosystem (Bronfenbrenner 1979). It is important to promote interventions that, working on prejudice reduction, could create contexts in which adolescents from migrant families can more freely explore various options in order to form their personal identity (Schwartz and Montgomery 2002). With respect to this, available evidence demonstrates the effectiveness of mass-media communications (Paluck 2009) and inter-group contacts (for a meta-analysis see Pettigrew and Tropp 2006) for reducing prejudices against ethnic minority groups.

Summing up, interventions at different levels (microsystems, mesosystem, and macrosystem) might create contexts that support adolescents from migrant families in alleviating cultural identity problems as well as in finding a personal identity coherence (Schwartz and Pantin 2006). 
Limitations and Suggestions for Future Research

This study should also be considered in light of some limitations. First, we employed a cross-sectional design, so we cannot ascertain developmental identity trajectories displayed by adolescents from Italian, mixed, and migrant families. Thus, future investigations could adopt a longitudinal design to examine identity formation in these groups. In this way it would be possible to determine whether adolescents from Italian, mixed, and migrant families present different identity paths over time, and which factors are at the basis of identity transitions.

Second, in this contribution we considered only one type of mixed families, defined on the basis of parents' nationality. Nevertheless, other forms of mixed families can be evaluated (i.e., interfaith, interethnic, and interracial families). Therefore, future investigations could test whether our findings related to the mixed family group are replicated taking into account other forms of mixed families.

Third, in this investigation we did not consider some variables related to the story and living conditions of migrant families that could have moderated the findings (e.g., how long has each family lived in Italy? How often have they migrated (across how many countries)? What was the age of the children/youth when they migrated to Italy? How many siblings in each family? Is there extended family nearby? What is the language competence of each family member? What is the degree of acculturation for each family member or subsystem of the family?). Thus, future studies could take into account these variables to test whether they moderate identity formation in adolescents from migrant families, in order to individuate more specific protective and risk factors.

Finally, in this study we collected only quantitative data. It would be worthwhile to integrate them with qualitative data (Waszak and Sines 2003; Watzlawick and Born 2007). In this way it could be possible to capture perspectives of adolescents from migrant families in order to better understand the specific difficulties they face in defining their identities.

\section{Conclusion}

Italy is a country in which the population growth is completely due to migrant families and their birth rate (ISTAT 2008b). Therefore, it is an urgent challenge to understand how children from migrant families develop their own identities. In this contribution we have found that adolescents from migrant families (especially Asian adolescents) face more difficulties in defining their identity, as they reconsider their choices to a greater extent than their peers from mixed and Italian families. Moreover, adolescents from migrant families are often in a status of searching moratorium, indicating that they are going through an identity crisis. This condition of identity instability, even though in the longterm can foster a firm identity development, in the short-term is associated with distress and with internalizing as well as externalizing problem behaviors (Schwartz et al. 2009). Therefore, it would be important to promote interventions aimed at supporting these adolescents in their identity formation process.

\section{References}

Abraham, K. G. (1986). Ego-identity differences among Anglo-American and Mexican American adolescents. Journal of Adolescence, 9, 151-166. 
Adams, G. R., \& Marshall, S. K. (1996). A developmental social psychology of identity: Understanding the person-in-context. Journal of Adolescence, 19, 429-442.

Battistich, V., Schaps, E., \& Wilson, N. (2004). Effects of an elementary school intervention on students' "connectedness" to school and social adjustment during middle school. Journal of Primary Prevention, 24, 243-262.

Baumeister, R. F. (1987). How the self became a problem: A psychological review of historical research. Journal of Personality and Social Psychology, 52(1), 163-176.

Baumeister, R. F., \& Muraven, M. (1996). Identity as adaptation to social, cultural, and historical context. Journal of Adolescence, 19, 405-416.

Berman, S., Montgomery, M., \& Kurtines, W. (2004). The development and validation of a measure of identity distress. Identity: An International Journal of Theory and Research, 4, 1-8.

Berman, A., Schwartz, S., Kurtines, W., \& Berman, S. (2001). The process of exploration in identity formation: The role of style and competence. Journal of Adolescence, 24, 513-528.

Berman, S. L., Weems, C. F., \& Petkus, V. (2009). The prevalence and incremental validity of identity problem symptoms in a high school sample. Child Psychiatry and Human Development, 40, 183-195.

Berry, J. W. (2001). A psychology of immigration. Journal of Social Issue, 57, 615-631.

Berzonsky, M. D. (2003). Identity style and well-being: Does commitment matter? Identity: An International Journal of Theory and Research, 3, 131-142.

Bosma, H. A. (1985). Identity development in adolescents: Coping with commitments. Unpublished doctoral dissertation, University of Groningen, The Netherlands.

Bosma, H. A., \& Kunnen, S. E. (2001). Determinants and mechanisms in ego identity development: A review and synthesis. Developmental Review, 21, 39-66.

Branch, C. W., Tayal, P., \& Triplett, C. (2000). The relationship of ethnic identity and ego identity status among adolescents and young adults. International Journal of Intercultural Relations, 24, 777-790.

Bronfenbrenner, U. (1979). The ecology of human development: Experiments by nature and design. Cambridge, London: Harvard University Press.

Crocetti, E., Rubini, M., Luyckx, K., \& Meeus, W. (2008a). Identity formation in early and middle adolescents from various ethnic groups: From three dimensions to five statuses. Journal of Youth and Adolescence, 37, 983-996.

Crocetti, E., Rubini, M., \& Meeus, W. (2008b). Capturing the dynamics of identity formation in various ethnic groups: Development and validation of a three-dimensional model. Journal of Adolescence, 31(2), 207-222.

Crocetti, E., Schwartz, S., Fermani, A., Klimstra, T., \& Meeus, W. (2010a). A cross-cultural comparison of identity statuses between two European countries. Manuscript submitted for publication.

Crocetti, E., Schwartz, S., Fermani, A., \& Meeus, W. (2010b). The Utrecht management of identity commitments scale (U-MICS): Italian validation and cross-national comparisons. European Journal of Psychological Assessment, 26(3), 169-183.

Erikson, E. (1950). Childhood and society. New York: Norton.

Erikson, E. (1968). Identity, youth and crisis. New York: Norton.

Ferrer-Wreder, L., Lorente, C., Kurtines, W., Briones, E., Bussel, J., Berman, S., et al. (2002). Promoting identity development in marginalized youth. Journal of Adolescent Research, 17, 168-187.

Goossens, L., \& Luyckx, K. (2007). Identity development in college students: Variable-centered and personcentered analyses. In M. Watzlavick \& A. Born (Eds.), Capturing identity. Quantitative and qualitative methods (pp. 105-118). Lahnam, Maryland: University Press of America.

Gore, P. A., Jr. (2000). Cluster analysis. In H. E. A. Tinsley \& S. D. Brown (Eds.), Handbook of applied multivariate statistics and mathematical modeling (pp. 297-321). San Diego, CA: Academic Press.

Gozzoli, C., \& Regalia, C. (2005). Migrazioni e famiglie [Migrations and families]. Bologna: il Mulino.

Grotevant, H. D. (1987). Toward a process model of identity formation. Journal of Adolescent Research, 2, 203-222.

Grove, K. J. (1991). Identity development in interracial Asian/White late adolescents: Must it be so problematic? Journal of Youth and Adolescence, 20, 617-628.

Hernandez, L., Montgomery, M. J., \& Kurtines, W. M. (2006). Identity distress and adjustment problems in at-risk adolescents. Identity: An International Journal of Theory and Research, 6, 27-33.

ISTAT. (2008a). Annuario statistico italiano [Statistical Italian yearbook]. Roma: Istituto Nazionale di Statistica [National Institute of Statistics]. Available online at http://www.istat.it/.

ISTAT. (2008b). Rapporto annuale [Annual report]. Roma: Istituto Nazionale di Statistica [National Institute of Statistics]. Available online at http://www.istat.it/.

Ketner, S., Buitelaar, M., \& Bosma, H. (2004). Identity strategies among adolescent girls of Moroccan descent in the Netherlands. Identity: An International Journal of Theory and Research, 4, 145-169.

King, R. (1993). Recent immigration to Italy: Character, causes and consequences. GeoJournal, 30, $283-292$. 
Kosic, A., Mannetti, M., \& Sam, D. L. (2005). The role of majority attitudes towards out-group in the perception of the acculturation strategies of immigrants. International Journal of Intercultural Relations, 29, 273-288.

Kroger, J. (2003). Identity development during adolescence. In G. R. Adams \& M. D. Berzonsky (Eds.), Blackwell handbook of adolescence (pp. 205-226). Malden, MA: Blackwell.

Kroger, J. (2004). Identity in adolescence: The balance between self and other (3rd ed.). London, New York: Routledge.

Kurtines, W. M., Montgomery, M. J., Eichas, K., Ritchie, R., Garcia, A., Albrecht, R., et al. (2008). Promoting positive identity development in troubled youth: A developmental intervention science outreach research approach. Identity: An International Journal of Theory and Research, 8, 125-138.

Luyckx, K., Goossens, L., \& Soenens, B. (2006). A developmental contextual perspective on identity construction in emerging adulthood: Change dynamics in commitment formation and commitment evaluation. Developmental Psychology, 42, 366-380.

Luyckx, K., Schwartz, S. J., Berzonsky, M. D., Soenens, B., Vansteenkiste, M., Smits, I., et al. (2008). Capturing ruminative exploration: Extending the four-dimensional model of identity formation in late adolescence. Journal of Research in Personality, 42(1), 58-82.

Mancini, T. (2007). Identità etnica. Un'analisi della letteratura psicologica [Ethnic identity. An analysis of the psychological literature]. Psicologia sociale, 1, 69-103.

Marcia, J. E. (1966). Development and validation of ego-identity status. Journal of Personality and Social Psychology, 3, 551-558.

Marcia, J. E. (1993). The status of the statuses: Research review. In J. E. Marcia, A. S. Waterman, D. R. Matteson, S. L. Archer, \& J. L. Orlofsky (Eds.), Identity: A handbook for psychosocial research (pp. 22-41). New York: Springer.

Meeus, W. (1996). Studies on identity development in adolescence: An overview of research and some new data. Journal of Youth and Adolescence, 25, 569-598.

Meeus, W. (in press). The study of adolescent identity formation 2000-2010. A review of longitudinal and narrative research. Journal of Research on Adolescence.

Meeus, W., Iedema, J., Helsen, M., \& Vollebergh, W. (1999). Patterns of adolescent identity development: Review of literature and longitudinal analysis. Developmental Review, 19, 419-461.

Meeus, W., Iedema, J., \& Maassen, G. H. (2002). Commitment and exploration as mechanisms of identity formation. Psychological Reports, 90, 771-785.

Meeus, W., van de Schoot, R., Keijsers, L., Schwartz, S. J., \& Branje, S. (in press). On the progression and stability of adolescent identity formation. A five-wave longitudinal study in early-to-middle and middle-to-late Adolescence. Child Development.

Paluck, E. L. (2009). Reducing intergroup prejudice and conflict using the media: A field experiment in Rwanda. Journal of Personality and Social Psychology, 96, 574-587.

Pettigrew, T. F., \& Tropp, L. R. (2006). A meta-analytic test of intergroup contact theory. Journal of Personality and Social Psychology, 90, 751-783.

Phalet, K., \& Schönpflug, U. (2001). Intergenerational transmission of collectivism and achievement values in two acculturation contexts. Journal of Cross-Cultural Psychology, 32, 186-201.

Rotheram-Borus, M. J. (1989). Ethnic differences in adolescents' identity status and associated behavior problems. Journal of Adolescence, 12, 361-374.

Salmivalli, C., \& Isaacs, J. (2005). Prospective relations among victimization, rejection, friendlessness, and children's self- and peer-perceptions. Child Development, 76, 1161-1171.

Schwartz, B. (2000). Self-determination: The tyranny of freedom. American Psychologist, 55, 79-88.

Schwartz, S. J. (2001). The evolution of Eriksonian and neo-Eriksonian identity theory and research: A review and integration. Identity: An International Journal of Theory and Research, 1, 7-58.

Schwartz, S. J. (2005). A new identity for identity research: Recommendations for expanding and refocusing the identity literature. Journal of Adolescent Research, 20, 293-308.

Schwartz, S. J., \& Montgomery, M. J. (2002). Similarities or differences in identity development? The impact of acculturation and gender on identity process and outcomes. Journal of Youth and Adolescence, 31, 359-372.

Schwartz, S. J., \& Pantin, H. (2006). Identity development in adolescence and emerging adulthood: The interface of self, context, and culture. In A. Prescott (Ed.), The concept of self in psychology (pp. 4585). Hauppage, NY: Nova Science Publishers.

Schwartz, S. J., Zamboanga, B. L., Weisskirch, R. S., \& Rodriguez, L. (2009). The relationships of personal and ethnic identity exploration to indices of adaptive and maladaptive psychosocial functioning. International Journal of Behavioral Development, 33, 131-144.

Stephen, J., Fraser, E., \& Marcia, J. E. (1992). Moratorium-achievement (Mama) cycles in lifespan identity development: Value orientations and reasoning system correlates. Journal of Adolescence, 15, 283-300. 
Streitmatter, J. (1988). Ethnicity as a mediating variable of early adolescent identity development. Journal of Adolescence, 11, 335-346.

Tajfel, H. (1981). Human groups and social categories. Cambridge: Cambridge University Press.

Triandis, H. C. (2001). Individualism-collectivism and personality. Journal of Personality, 69(6), 907-924.

Verkuyten, M., \& Kinket, B. (2000). Social distances in a multi ethnic society: The ethnic hierarchy among Dutch preadolescents. Social Psychology Quarterly, 63, 75-85.

Voci, A., \& Hewstone, M. (2003). Intergroup contact and prejudice towards immigrants in Italy: The mediational role of anxiety and the moderational role of group salience. Group Processes and Intergroup Relations, 6, 37-54.

von Eye, A., \& Bogat, A. (2006). Person-oriented and variable-oriented research: Concepts, results, and development. Merrill-Palmer Quarterly, 52, 390-420.

Waszak, N. K., \& Sines, M. C. (2003). Mixed methods in psychological research. In A. Tashakkori \& C. Teddlie (Eds.), Handbook of mixed methods in social and behavioral research (pp. 557-576). Thousand Oaks, CA: Sage.

Watzlawick, M., \& Born, A. (Eds.). (2007). Capturing identity. Quantitative and qualitative methods. Lahnam, Maryland: University Press of America. 